\title{
Review: hip protectors reduce hip fractures after falls in elderly people living in institutions or supported home environments
}

Parker MJ, Gillespie LD, Gillespie WJ. Hip protectors for preventing hip fractures in the elderly. Cochrane Database Syst Rev 2001;(2):CD001255 (latest version 1 Mar 2001).

\section{QUESTION: Do external hip pads or protectors reduce hip fractures after falls in elderly people?}

\section{Data sources}

Studies were identified by searching the Cochrane Musculoskeletal Injuries Group specialised register (December 2000), the Cochrane Controlled Trials Register (Issue 4, 2000), Medline (1966-2000), EMBASE/ Excerpta Medica (1988-2000), CINAHL (1982-2000); reviewing bibliographies of retrieved articles; and contacting authors of identified trials.

\section{Study selection}

Randomised and quasi-randomised controlled trials that compared use of hip protectors with no protectors in elderly people living in the community or in institutional care. Outcomes of interest were incidence of hip fractures, pubic rami and other pelvic fractures, other fractures, reported falls, mortality, patient compliance, and complications.

\section{Data extraction}

Data were extracted on participants, intervention (type of hip protector), outcomes, and length of follow up. 2 reviewers independently assessed the methodological quality of each trial on the basis of 10 criteria (main criterion was concealment of allocation). Maximum quality score was 12.

\section{Main results}

7 trials $(\mathrm{n}=3553)$ met the selection criteria. Mean quality score was $\{6.3$ out of 12 (range 5-8) $\}$ *. Participants were residents of rest or nursing homes or were frail elderly adults living at home with support. All studies used hip pads placed in the region of the greater trochanter, and 6 had the pads fixed or sewn into special underwear. 4 used an energy shunting design, 1 used an energy absorbing design, 1 used no special fixation method, and 1 used an undeterminable design.

1 study focused on compliance with hip protectors, and was therefore excluded from the analysis of effectiveness. Each of the 6 remaining studies found a reduced incidence of hip fracture in people who used hip protectors. The 3 larger studies $(n=3210)$ used cluster randomisation (randomised by nursing home, ward, or treatment unit), and therefore, data from these studies could not be pooled. Meta-analysis of data from the 3 smaller trials that randomised individual patients $(n=202)$ showed that patients allocated to hip protectors had fewer hip fractures than those allocated to no hip protectors (table). Each of 3 studies found no difference in the incidence of pelvic fractures. As well, each of 3 studies found no difference in other types or unspecified types of fractures. 5 studies reported similar proportions of falls in the treatment and control groups, and 1 study found no difference in mortality at 1 year. Estimates of patient compliance rates ranged from $24 \%$ to $86 \%$. Complications associated with hip protectors were reported in 3 studies and included skin irritation or abrasion, discomfort, leg swelling, and bowel irritation.

\section{Conclusion}

External hip protectors reduce the incidence of hip fracture after falls in elderly people living in institutions or supported home environments.

*Calculated from data in article.

Source of funding: no external funding.

For correspondence: Dr MJ Parker Orthopaedic Department, Peterborough District Hospital, Thorpe Road, Peterborough,

Cambridgeshire PE3 6DA, UK. Fax +44 (0)1733875013.

Hip protectors v no hip protectors in elderly people living in institutions or supported home environmentst

\begin{tabular}{lllll} 
& \multicolumn{2}{c}{ Weighted event rates } & & \\
\cline { 2 - 4 } $\begin{array}{c}\text { Outcome at 9-19 } \\
\text { months }\end{array}$ & $\begin{array}{l}\text { Hip } \\
\text { protectors }\end{array}$ & $\begin{array}{l}\text { No hip } \\
\text { protectors }\end{array}$ & RRR (95\% Cl) & NNT (CI) \\
\hline Hip fracture & $4 \%$ & $17 \%$ & $76 \%(35$ to 91$)$ & $8(5$ to 23$)$ \\
\hline
\end{tabular}

†Abbreviations defined in glossary; RRR, NNT, and $\mathrm{Cl}$ calculated from data in article. Meta-analysis was done using a fixed effects model.

\section{COMMENTARY}

Up to 14000 people die each year in the UK as a result of osteoporotic hip fractures. ${ }^{1}$ Residents in nursing homes or other forms of institutionalised care are at particularly high risk of hip fracture. The National Service Framework (NSF) for older people outlines measures to reduce the number of falls and their effect on hip fractures. ${ }^{1}$ The NSF stresses the need for implementation of specialist falls services for risk assessment and secondary prevention strategies such as hip protectors.

The review by Parker $e t$ al presents the evidence available on the benefits of using hip protectors in patients living in institutionalised care. However, some of the trials had poor methodological quality. For example, none of the studies had clearly concealed allocation. As the average compliance rate in the 6 reviewed studies was only $53 \%$, the question of compliance needs to be addressed, with an emphasis on product design and patient acceptability. Reasons for non-compliance included complaints that hip protectors were "too hot", "uncomfortable", and "irritating on the skin". In my own experience, many patients with continence problems would prefer protectors in dark colours rather than white, which is the only colour available. Such compliance issues should be addressed in studies of the effectiveness of hip protectors among patients residing in their own homes.

A demand clearly exists for the use of hip protectors in institutionalised care. The use of hip protectors could be integrated into falls assessment tools whereby patients identified as having a high risk of fracture could be targeted and offered specialist advice, with the option of using hip protectors and other preventative interventions. $^{2}$

Ruth Hildreth, RGN Orthopaedic Research Nurse, University of York, York, UK

1 National Service Framework for Older People. Standard Six: Falls. London: Department of Health, March 2001:76-89. http://www.doh.gov.uk/nsf/olderpeople.htm

2 National Osteoporosis Society. Accidents, falls, fractures and osteoporosis. A strategy for primary care groups. Bath: National Osteoporosis Society, January 2000. 